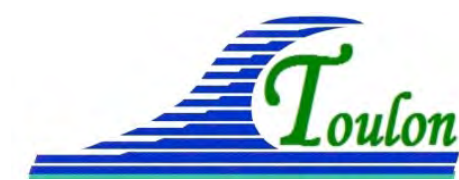

XIV èmes Journées Nationales Génie Côtier - Génie Civil

Toulon, 29 juin au $1^{\text {er }}$ juillet 2016

DOI:10.5150/jngcgc.2016.008 (C) Editions Paralia CFL

disponible en ligne - http://www.paralia.fr - available online

\title{
Two-phase flow simulation of scour around a cylindrical pile
}

\section{Tim NAGEL ${ }^{1}$, Julien CHAUCHAT ${ }^{1}$, Zhen CHENG ${ }^{2}$, Xiaofeng LIU $^{3}$, Tian-Jian HSU ${ }^{2}$, Cyrille BONAMY ${ }^{4}$, Olivier BERTRAND ${ }^{5}$}

1. Université. Grenoble Alpes, LEGI, F-38000 Grenoble, France.

tim.nagel@univ-grenoble-alpes.fr

2. Center for Applied Coastal Research, University of Delaware, Newark, DE 19716, USA.

3. Dept. of Civil and Environmental Engineering, Pennsylvania State University, State College, PA 16802, USA.

4. CNRS, LEGI, F-38000 Grenoble, France.

5. ARTELIA 38130 Échirolles, France.

\begin{abstract}
:
In this contribution we present the validation of different OpenFoam solvers and turbulence models for application to scour under steady current. The final goal is to demonstrate the applicability of the two-phase flow Eulerian approach for scour simulations. The hydrodynamic model has been validated using ROULUND et al. (2005) experimental and numerical data for flow around a vertical cylinder over a smooth bed. The preliminary result of the two-phase flow simulation of scour is also presented but more work has to be done.
\end{abstract}

Keywords: Two-phase flow, Scour, Numerical modeling.

\section{Introduction}

The presence of a structure in a river or marine environment may significantly affect the flow in its vicinity such as, the contraction of the flow; the formation of a horseshoe vortex in front of the structure; the formation of vortex flow pattern (usually with vortex shedding) behind the structure; the generation of turbulence. In the case of an erodible bed, all these effects may induce an increase of the sediment transport around the structure and the formation of a scour hole. As scour may induce failure of the structure that can have disastrous human and financial consequences, it is a very important problem for civil engineer.

BRIAUD et al. (1999) have established that from 1970 to 2000, scour around bridge pier was responsible of $60 \%$ of the bridges failure in the United States. The associated cost to these scour failure is estimated at US\$ 50M per year (LAGASSE et al., 1995). Coastal areas are also impacted, repairing coastal structure failure due to scouring has been estimated at US\$2-10 million per failure (HUGHES, 1993). Furthermore, the cost of a wind turbine foundation is more than $30 \%$ of its total cost in environments where waves and currents are energetic (SUMER, 2007). 
A complete review of the cutting-edge scour modeling can be found in SUMER (2007). After decades of extensive research, the state of the art model predictions are not sufficient. If classical model approaches allow a partial answer to the scour problem, several limitations remains. Indeed, these classical models are based on empirical bedload formulas (MEYER-PETER \& MÜLLER, 1948; ENGELUND \& FREDSØE, 1976) that has been obtained under steady and uniform flow conditions where the turbulence is generated by a fully-developed boundary layer. In the case of scour around an obstacle, the horseshoe vortex usually modifies the turbulence so that the classical formulas are used out of their validity range, especially for deep scour hole. In the past decade, significant research efforts have been devoted to modeling sediment transport using multiphase approaches. Recently, an open-source multi-dimensional Reynoldsaveraged two-phase sediment transport model, sedFoam, is developed by the authors (CHENG \& HSU, 2014) and it has been adopted by many researchers to study momentary bed failure (CHENG et al., 2014) and granular rheology in sheet flow (REVIL-BAUDARD \& CHAUCHAT, 2013) for example. The two-phase flow approach does not require to use the empirical sediment transport rate and erosiondeposition laws and no additional equation has to be solved for the bed evolution (Exner equation). In other words, conventional bedload and suspended load assumptions are not needed. The physical grounds on which this new generation of sediment transport model are based on, should help to improve scour morphological evolution predictions, especially for complex geometries and/or flow forcings (waves and tides).

We further apply this model to the scour problem. Our primary goal is to demonstrate the applicability of the two-phase flow Eulerian approach for scour simulations. This paper focuses on the hydrodynamic model validation, using ROULUND et al. (2005) experimental and numerical data for flow around a vertical cylinder and smooth bed. The first two-phase flow simulation of scour around a cylinder will be presented. However, for the two-phase flow model, no comparison with ROULUND et al. (2005) can be presented for the moment as computations are still running.

\section{Numerical model and setup}

As in ROULUND et al. (2005) work, two different geometries and parameters sets are used for clear water (hydrodynamic model) and live-bed cases (two-phase flow model). The hydrodynamic model validation is done using SIMPLE and PIMPLE solvers from OpenFOAM (WELLER et al., 1998) whereas the two-phase flow computations are performed using sedFoam. As a strong adverse pressure gradient is responsible for the horseshoe vortex formation in front of the pile, ROULUND et al. (2005) recommends the use of a k- $\omega$ SST model (MENTER, 1993) to solve the Reynolds-Averaged NavierStokes (RANS) equations. However, $\mathrm{k}-\omega$ closure has not been completely validated into sedFOAM and up to now only a k- $\varepsilon$ model is available. Therefore, we compare the two aforementioned turbulence models. 


\section{XIV èmes Journées Nationales Génie Côtier - Génie Civil \\ Toulon, 29 juin au $1^{\text {er }}$ juillet 2016}

\subsection{Hydrodynamic model}

In the clear water configuration, the models solve the 3D incompressible Navier- Stokes equations and all the computations are non-dimensionalized by the pile diameter $\mathrm{D}$ $(\mathrm{D}=53.6 \mathrm{~cm})$. The vertical 1D set-up is a classical boundary layer case. The water column is divided in 64 elements, with a constant cell growth rate gz $\left(=1 \times 10^{-2}\right)$ along the vertical direction. For both models, a given non-dimensional roughness height $\left(\mathrm{ks} / \mathrm{D}=1.8 \times 10^{-3}\right)$ is imposed at the wall in order to parametrize the viscous sublayer behavior. For the k- $\omega$ SST model, ks is applied through a tuned $\omega$-wall function (ROULUND et al., 2005) and for the k- $\varepsilon$ model, the wall roughness is specified via the turbulent viscosity (TAPIA, 2009). Concerning the latter, two parameters are needed, ks and the roughness constant $\mathrm{Cs}(\mathrm{Cs}=0.05)$.

The 3D computational domain is presented in figure 1. The domain dimensions are $\mathrm{Lx}=\mathrm{Ly}=20 \mathrm{D}$ and $\mathrm{Lz}=1 \mathrm{D}$ in $\mathrm{x}, \mathrm{y}$ and $\mathrm{z}$ directions, respectively. The structured mesh contains 724992 elements (32 vertical elements, similar to ROULUND et al. (2005) mesh for steady computations using simpleFoam) or 3866624 elements (64 vertical elements, refined mesh mainly for unsteady computations, using pimpleFoam). The mesh is refined in the cylinder region. At the walls (bottom and cylinder), a boundary layer mesh type is used with the same $\mathrm{z}^{+}\left(\mathrm{z}^{+}=\mathrm{zu} \tau / v\right.$, where $\mathrm{u} \tau$ is the friction velocity) as in 1D. The boundary conditions are shown in figure 1 and are the ones described by ROULUND et al. (2005), except at the inlet, where the 1D profiles computed with boundaryFoam are imposed. At the walls, $\omega$ and $\varepsilon$ are imposed via the tuned wall functions described previously, with $\mathrm{ks} / \mathrm{D}=1 \times 10^{-4}$ for the cylinder, considered as smooth.

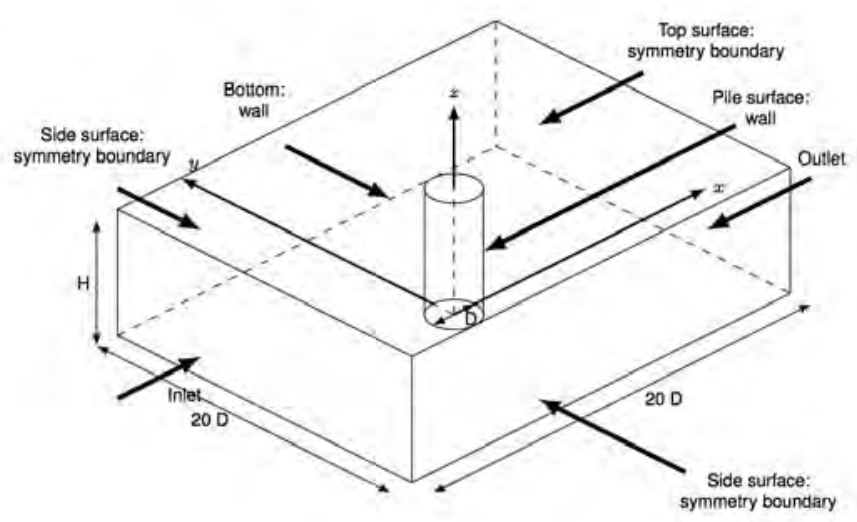

Figure 1. Sketch of the boundary conditions implemented in the numerical model, illustration is adapted from ROULUND et al. (2005). 


\subsection{Two-phase flow model}

The pile diameter in ROULUND et al. (2005) live-bed configuration is equal to $0.1 \mathrm{~m}$. In order to reduce the runtime, the computational domain size has been reduced in this configuration, the domain dimensions are $\mathrm{Lx}=\mathrm{Ly}=10 \mathrm{D}$ and $\mathrm{Lz}=3 \mathrm{D}$. The sediment height $h_{s}$ is equal to $1 D$. An hyperbolic tangent profile of sediment concentration is imposed at the interface for initial conditions and the flow is generated by a pressure gradient. More details on the k- $\varepsilon$ version of sedFoam can be found in CHENG \& HSU (2014).

\section{Results and discussion}

\subsection{Hydrodynamic model validation}

Figure 2 shows the comparison between OpenFOAM and ROULUND et al. (2005) results for both k- $\omega$ SST and k- $\varepsilon$ models. From left to right are represented the velocity profile as a function of $\mathrm{z}^{+}$, the linear velocity profile and the dimensionless turbulent kinetic energy $\left(\mathrm{k} / \mathrm{u} \tau^{2}\right)$.

Provided that the bottom boundary conditions are parameterized correctly, both turbulence models are able to reproduce 1D ROULUND et al. (2005) experimental results. Theses profiles are used as inlet conditions for 3D hydrodynamic computations.
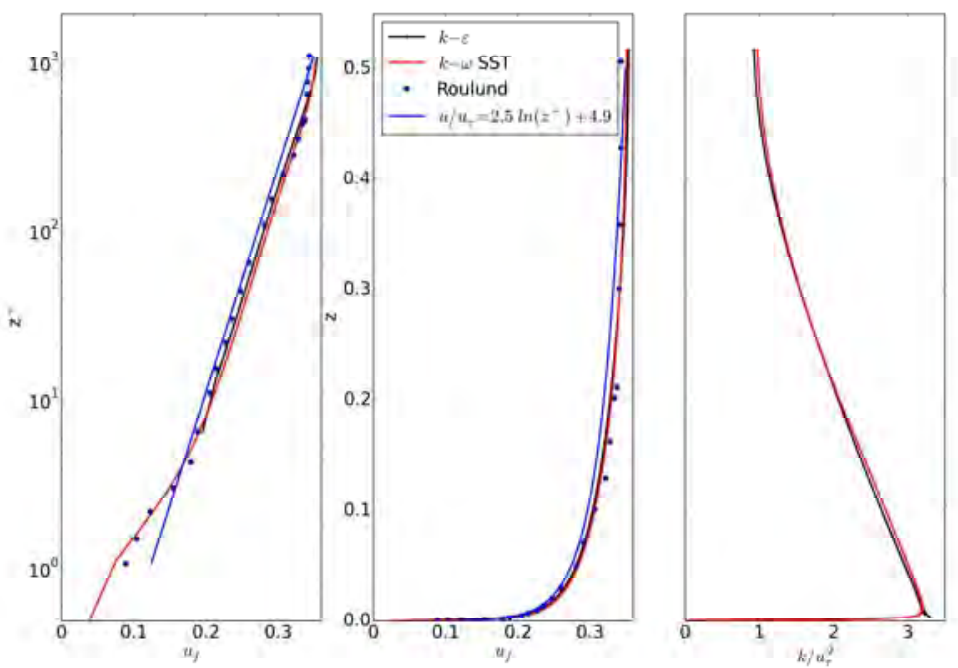

Figure 2. Comparison between OpenFoam and ROULUND et al. results for velocity profiles in log and linear scales and dimensionless turbulent kinetic energy using the $k-\omega$ SST and the $k-\varepsilon$ solvers.

Figure 3 shows a comparison of the present hydrodynamic model simulations with ROULUND et al. (2005) experimental and numerical results for longitudinal profiles of horizontal (top panel) and vertical (bottom panel) velocities in the plane of symmetry at different distances from the bed. Three models are tested, steady k- $\varepsilon$, steady k- $\omega$ SST 


\section{XIV ${ }^{\text {èmes }}$ Journées Nationales Génie Côtier - Génie Civil \\ Toulon, 29 juin au $1^{\text {er }}$ juillet 2016}

and unsteady k- $\omega$ SST, the latter is computed on a finer mesh. The results of the latter have been averaged over 20 vortex shedding periods in order to compared with averaged results from ROULUND et al. (2005).
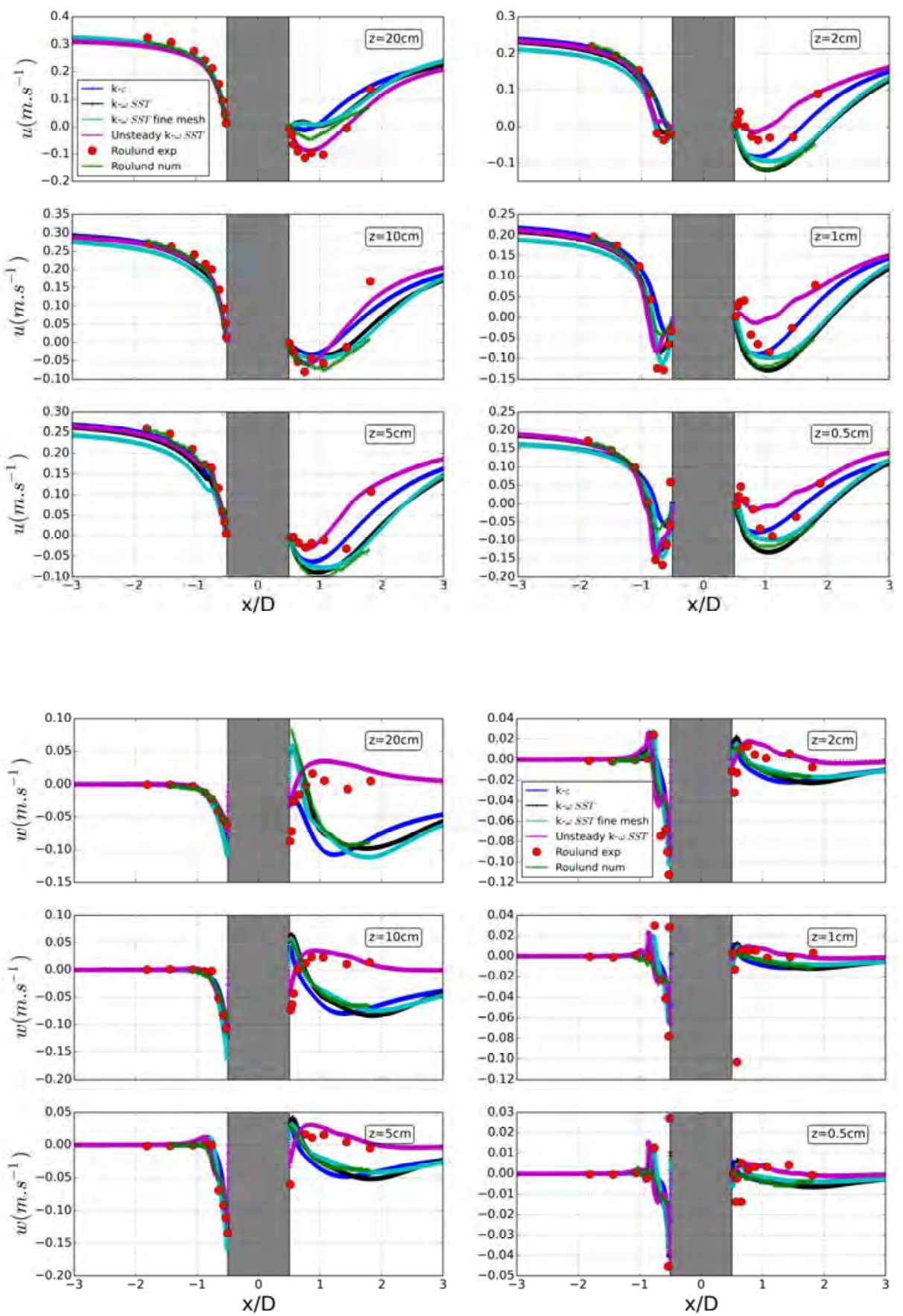

Figure 3. Horizontal and vertical velocities, $u$ (top) and $w$ (bottom), in the plane of symmetry at different distances from the bed. 


\section{Thème 1 - Hydrodynamique côtière}

There is a good agreement between ROULUND et al. (2005) results and the present model for the flow upstream of the pile. The horseshoe vortex is captured with all the models but only the two k- $\omega$ models allows more accurate prediction of velocity at small z values obtained by ROULUND et al. (2005). Concerning the downstream side of the pile, only the unsteady k- $\omega$ SST model agrees with ROULUND et al. (2005) experimental data, i.e. only this model is able to capture correctly the anti-clockwise circulation highlighted by the experimental results, even if an overprediction of the uvelocity component is observed in the nearbed region (figure 3 , top). The steady $\mathrm{k}-\omega$ SST model on coarse and fine meshes are extremely similar, showing the benefit of the use of an unsteady k- $\omega$ SST model, with the latter model, most of the numerically discrepancies reported in of ROULUND et al. (2005) can be overcome.

\subsection{Two-phase flow}

Two-phase flow computations are extremely time consuming, up to now only a few second of simulations have been carried out. Figure 4 shows the vertical elevation of the isosurface of concentration $\varphi=0.5$ which is a proxy for the quasistatic bed elevation field after 1.9s of simulation, obtained with the k- $\varepsilon$ version of sedFoam (which is not steady). The scour hole formation is clearly observed. The model has to be run over a longer duration to compare the predicted scour holes with measured data of ROULUND et al. (2005) measurements. For this configuration, the scour equilibrium depth is obtained after 2 hours of dynamics.

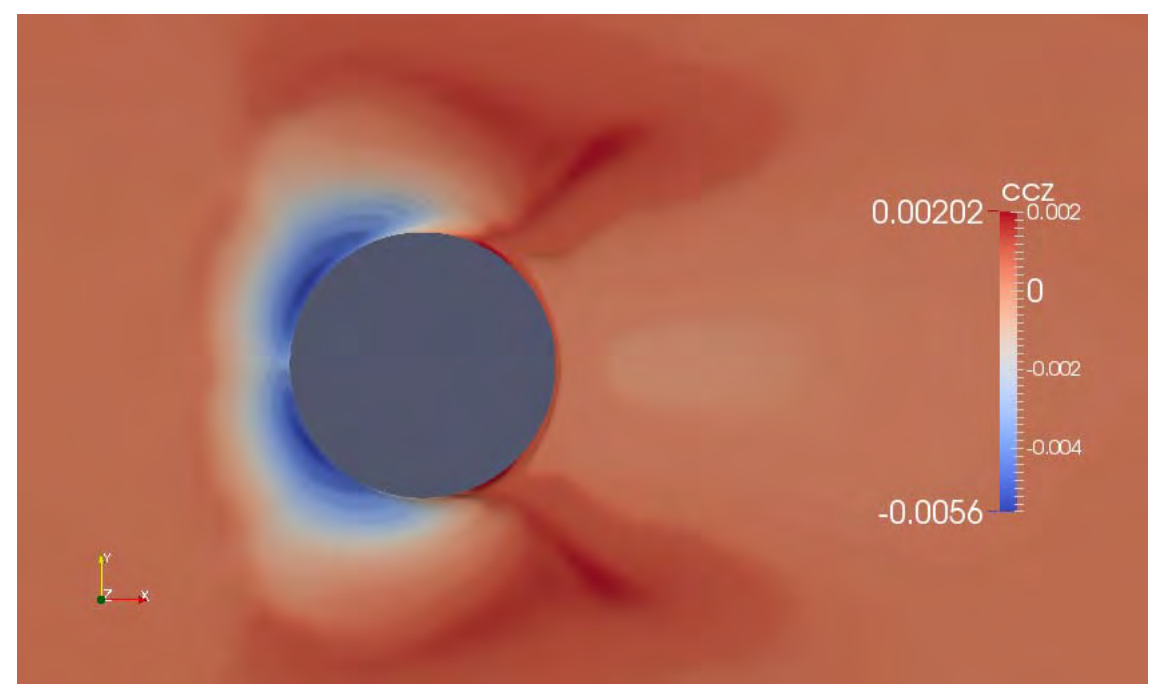

Figure 4. Bed elevation after 1.9s of scouring.

\section{Conclusions}

In this paper, the simple and pimple solvers of openFOAM have been validated on ROULUND et al. (2005) data for the hydrodynamic of the flow around a vertical 


\section{XIV èmes Journées Nationales Génie Côtier - Génie Civil \\ Toulon, 29 juin au $1^{\text {er }}$ juillet 2016}

cylinder. The unsteady k- $\omega$ SST models is shown to improve upon the steady state solver (simple) solution. Most of the discrepancies reported in ROULUND et al. (2005) can be overcome. Even if the k- $\varepsilon$ model results are the poorest obtained with the hydrodynamic model, their agreement with the measurements remains reasonable enough to use the $k-\varepsilon$ version of Sedfoam for scour. The preliminary results for scour prediction using the two-phase model seems promising but the model has to be run over a longer duration to compare the predictions with the experiments.

\section{Acknowledgment}

This work was supported by the French national program EC2CO-LEFE MODSED. The authors would also like to acknowledge the financial support from the Région Rhône-Alpes through the CMIRA COOPERA project and the ExploraPro grant of J. Chauchat. Most of the computations presented in this paper were performed using the CIMENT infrastructure (https://ciment.ujf-grenoble.fr), which is supported by the Rhône-Alpes région (GRANT CPER07-13 CIRA) and the GENCI/CINES under the allocation 2016-017567.

\section{References}

BRIAUD J.-L., TING F. C., CHEN H., GUDAVALLI R., PEREGU S., WEI G. (1999). Sricos: Prediction of scour rate in cohesive soils at bridge piers. Journal of Geotechnical and Geoenvironmental Engineering, Vol. 125(4), pp 237-246. http://dx.doi.org/10.1061/(ASCE)1090-0241(1999)125:4(237)

CHENG Z., HSU T.-J. (2014). A multi-dimensional two-phase eulerian model for sediment transport-twophase euler sedfoam (version 1.0). Tech. rep., Technical Report No. CACR-14-08, University of Delaware.

CHENG Z., HSU T.-J., CALANTONI J. (2014). Preliminary investigation of momentary bed failure using a multi-dimensional eulerian two-phase model. in AGU Fall Meeting Abstracts, Vol. 1, 3600 p.

ENGELUND F., FREDSØE J. (1976). A sediment transport model for straight alluvial channels. Hydrology Research, Vol. 7(5), pp 293-306.

HUGHES S. A. (1993). Physical models and laboratory techniques in coastal engineering. Vol. 7, World Scientific.

LAGASSE P., SCHALL J., JOHNSON F., RICHARDSON E., CHANG F. (1995). Stream stability at highway structures (2d ed.): Federal highway administration, hydraulic engineering circular no. 20. Tech. Rep., Publication FHWA-IP-90-014.

MENTER F. R. (1993). Zonal two equation k-turbulence models for aerodynamic flows. AIAA paper, 2906. http://dx.doi.org/10.2514/6.1993-2906

MEYER-PETER E., MÜLLER R. (1948). Formulas for bed-load transport. IAHR. 
REVIL-BAUDARD T., CHAUCHAT J. (2013). A two-phase flow model for sheet flow regime based on dense granular flow rheology. Journal of Geophysical Research: Oceans, Vol. 118(2), pp 619-634. http://dx.doi.org/10.1029/2012jc008306

ROULUND A., SUMER B., FREDSØE J., MICHELSEN J. (2005). Numerical and experimental investigation of flow and scour around a circular pile. Journal of Fluid Mechanics, Vol. 534, pp 351-401. http://dx.doi.org/10.1017/S0022112005004507

SUMER M. (2007). Mathematical modelling of scour: A review. Journal of Hydraulic Research, Vol. 45(6), pp 723-735. http://dx.doi.org/10.1080/00221686.2007.9521811

TAPIA X.P. (2009). Modelling of wind flow over complex terrain using openfoam. University of Gävle.

WELLER H. G., TABOR G., JASAK H., FUREBY C. (1998). A tensorial approach to computational continuum mechanics using object-oriented techniques. Computers in physics, Vol. 12(6), pp 620-631. http://dx.doi.org/10.1063/1.168744 